$\underline{\text { Supporting Information }}$

\title{
The Lithium Ion Hybrid Capacitor with a Scaffold Electrode of Tin Sulfide and Tin Metal and its Electrolyte Issue
}

Yu-Shun Luo, Dah-Shyang Tsai*, Chien-Chen Wang, Chun-Wei Chiang

Department of Chemical Engineering, National Taiwan University of Science and Technology, 43, Keelung Road, Section 4, Taipei, 10607 Taiwan

*Corresponding author, ORCID https://orcid.org/0000-0001-8067-9540

E-mail address: dstsai@mail.ntust.edu.tw

FAX: 886-2-27376644

Phone: 886-2-27376618

The diffraction patterns of $5 \mathrm{SnS}-5 \mathrm{Sn} / \mathrm{CNT}$ and $8 \mathrm{SnS}-2 \mathrm{Sn} / \mathrm{CNT}$ powders are plotted in Fig. S1. Both samples show the diffraction lines of $\alpha$ tin sulfide (JCPDS 75-1803) and $\beta$-tin (JCPDS 86-2265). The composition has been estimated with its EDX analysis result, confirmed by chemical analysis.

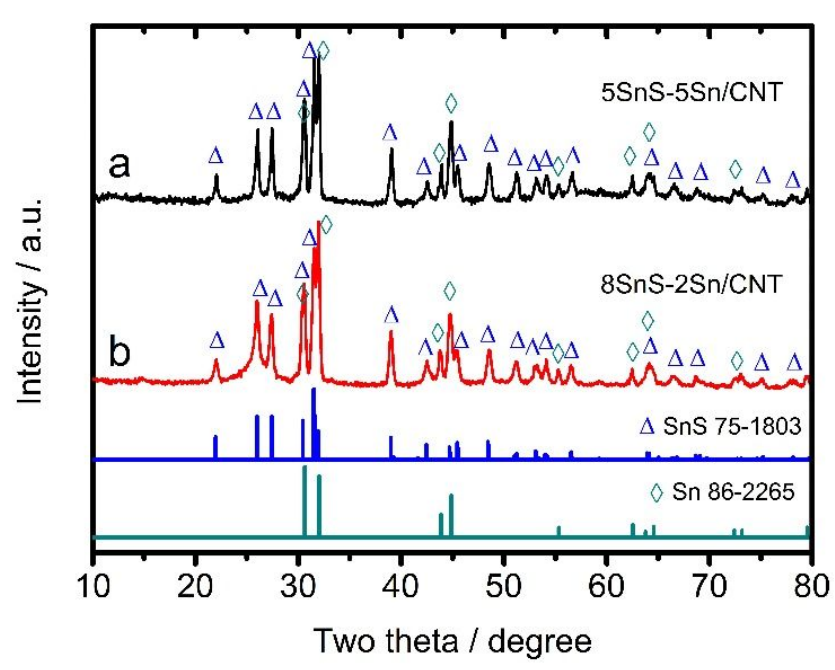

Fig. S1 XRD results of SnS-Sn/CNT. The diffraction patterns of (a) $5 \mathrm{SnS}-5 \mathrm{Sn} / \mathrm{CNT}$ and (b) $8 \mathrm{SnS}-$ $2 \mathrm{Sn} / \mathrm{CNT}$. The CNT scaffold has been acidified at $50{ }^{\circ} \mathrm{C}$ before soaking in the molten slag of tin and sulfur. 
In comparison with $5 \mathrm{SnS}-5 \mathrm{Sn} / \mathrm{CNT}$, the morphology of $8 \mathrm{SnS}-2 \mathrm{Sn} / \mathrm{CNT}$ displays less porosity, Fig. S2b. The coatings of $8 \mathrm{SnS}-2 \mathrm{Sn} / \mathrm{CNT}$ are thicker as well, before and after lithiation. We also note that the coating is strongly bonded to CNT, either $8 \mathrm{SnS}-2 \mathrm{Sn} / \mathrm{CNT}$ or $5 \mathrm{SnS}-5 \mathrm{Sn} / \mathrm{CNT}$, therefore, the repeated cycles of lithiation and delithiation do not cause the SnS-Sn coatings to peel off.
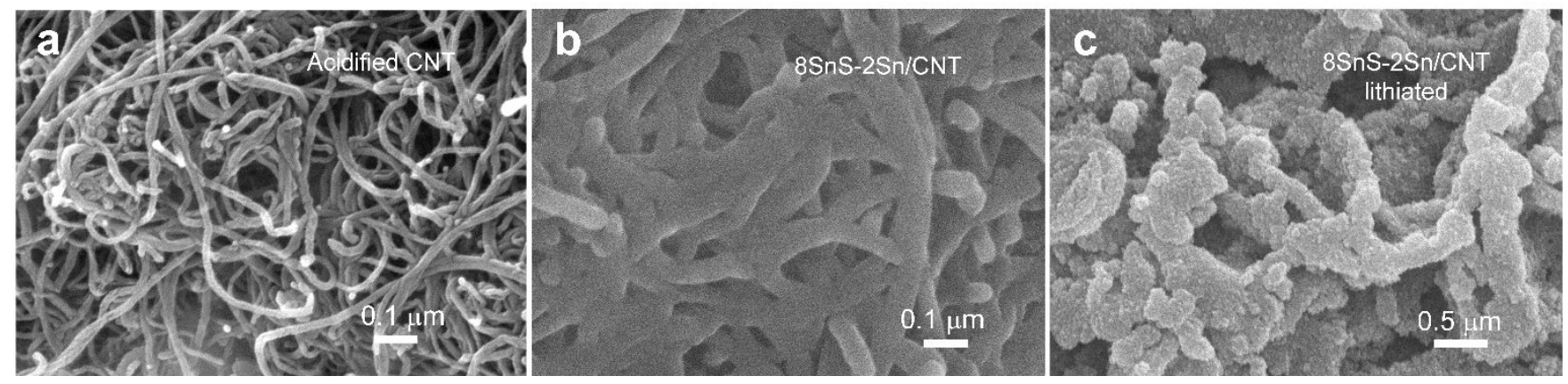

Fig. S2 Morphology of 8SnS-2Sn/CNT. SEM images of (a) multi-walled CNT, (b) 8SnS-2Sn/CNT before lithiation, (c) $8 \mathrm{SnS}-2 \mathrm{Sn} / \mathrm{CNT}$ after lithiation. Please note the scale bar of Fig. S2(c) is $0.5 \mu \mathrm{m}$, instead of $0.1 \mu \mathrm{m}$.

Two CV curves of 8SnS-2Sn/CNT are plotted in Fig. S3. The voltammogram of Fig. S3a is measured in the electrolyte of 1.0 M LiTFSI and 0.2 $\mathrm{M} \mathrm{LiNO}_{3}$, and that of Fig. S3b is measured in the electrolyte of 1.0 $\mathrm{M} \mathrm{LiPF}_{6}$. They are very similar to those shown in Fig. 3, CV of LiPF 6 is slightly thicker in enclosed area, compared with that of LiTFSI.
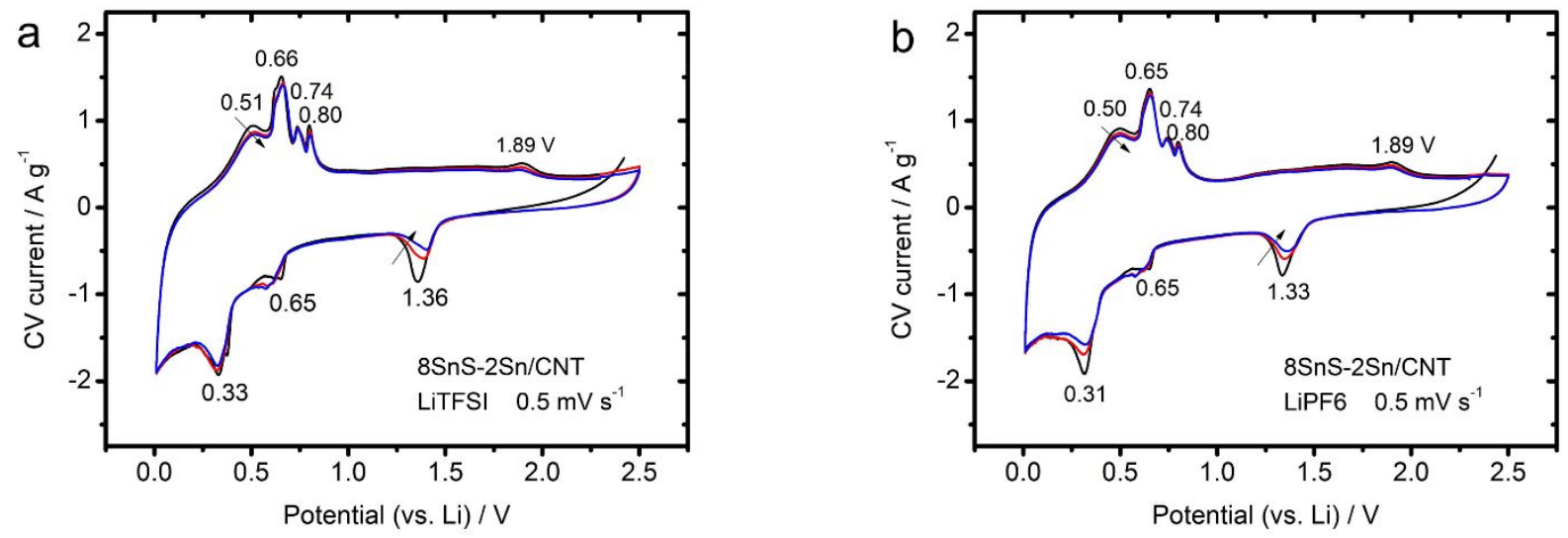

Fig. S3 CV results of $8 \mathrm{SnS}-2 \mathrm{Sn} / \mathrm{CNT}$. Voltammograms are scanned at $0.5 \mathrm{mV} \mathrm{s}^{-1}$, in the electrolyte of (a) $1.0 \mathrm{M} \mathrm{LiTFSI}$ and $0.2 \mathrm{M} \mathrm{LiNO}_{3}$ or (b) $1.0 \mathrm{M} \mathrm{LiPF}_{6}$. 
Comparison of the $\mathrm{CV}$ curves reveals the influences of electrode sulfur and the plausible existence of polysulfides. Fig. S4a contrasts the CV currents in the LiTFSI electrolyte and the $\mathrm{LiPF}_{6}$ electrolyte, showing that the $\mathrm{CV}$ current of $\mathrm{LiPF}_{6}$ is higher than that of LiTFSI between 1.25 and $2.5 \mathrm{~V}$. Fig. S4b points out the $\mathrm{CV}$ current of $8 \mathrm{SnS}-2 \mathrm{Sn} / \mathrm{CNT}$ is higher than that of $5 \mathrm{SnS}-5 \mathrm{Sn} / \mathrm{CNT}$. We attribute the higher CV currents to a small amount of polysulfides in the electrolyte. ${ }^{54}$

Most probably, the electrolyte polysulfides were produced in the prelithiation step of SnS-Sn/CNT electrode. Since the sulfur content of $8 \mathrm{SnS}-2 \mathrm{Sn} / \mathrm{CNT}$ is higher than $5 \mathrm{SnS}-5 \mathrm{Sn} / \mathrm{CNT}$, the amount of polysulfides is higher in the case of $8 \mathrm{SnS}-2 \mathrm{Sn} / \mathrm{CNT}$. On the other hand, $\mathrm{LiNO}_{3}$ can oxidize the polysulfides and diminish their concentrations, ${ }^{47}$ thus, the influences of polysulfides are less in the LiTFSI electrolyte, since the LiTFSI electrolyte also contains $0.2 \mathrm{M} \mathrm{LiNO}_{3}$, while the $\mathrm{LiPF}_{6}$ electrolyte does not.
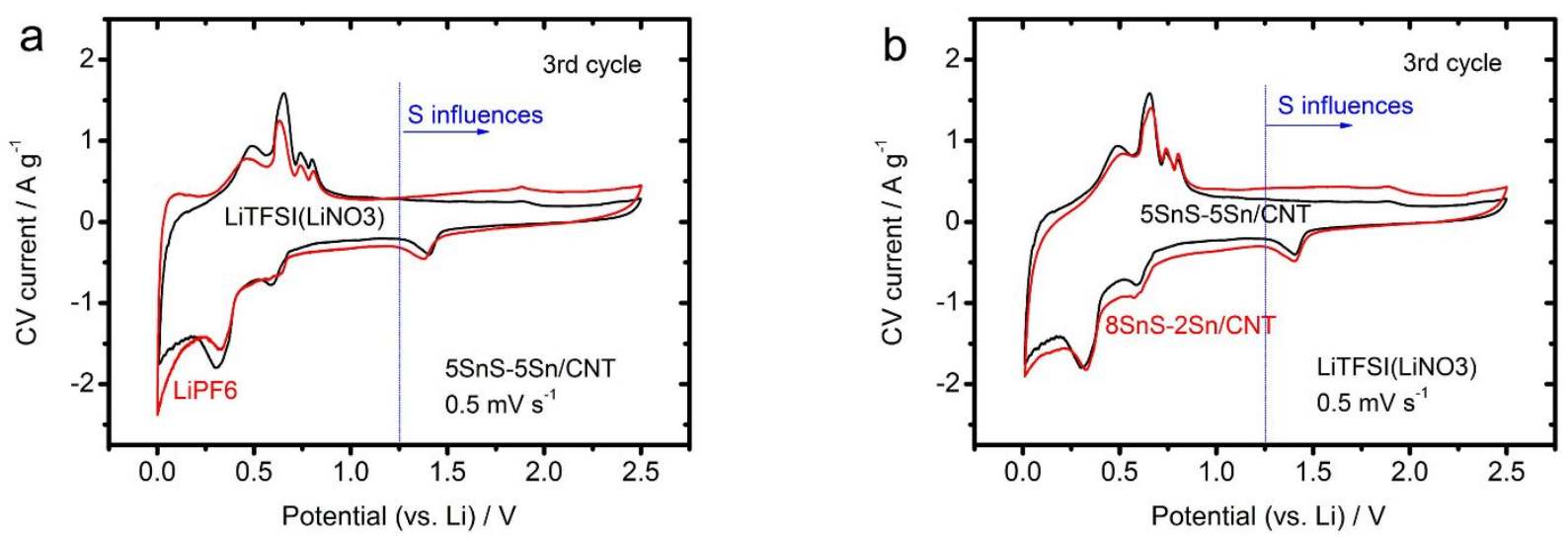

Fig. S4 Influences of electrode sulfur on CV between 1.25 and 2.5 V. Sulfur influences are visible when the $\mathrm{CV}$ currents are contrasted between (a) the LiTFSI electrolyte and the $\mathrm{LiPF}_{6}$ electrolyte for the $5 \mathrm{SnS}-5 \mathrm{Sn} / \mathrm{CNT}$ electrode, (b) the $8 \mathrm{SnS}-2 \mathrm{Sn} / \mathrm{CNT}$ electrode and the $5 \mathrm{SnS}-5 \mathrm{Sn} / \mathrm{CNT}$ electrode in the LiTFSI electrolyte. Either a higher sulfur content of electrode or an electrolyte without $\mathrm{LiNO}_{3}$ produces a higher CV current. The dashed lines show the region that sulfur influences are significant.

(54) Chen, S.; Dai, F.; Gordin M. L.; Wang, D. Exceptional Electrochemical Performance of Rechargeable Li-S Batteries with a Polysulfide Containing Electrolyte. RSC Adv. 2013, 3, 3540-3543.

The impedance results of two full cells of 4:1 mass ratio, soaked in LiTFSI and $\mathrm{LiPF}_{6}$, are contrasted in Fig. S5. The negative $5 \mathrm{SnS}-5 \mathrm{Sn} / \mathrm{CNT}$ electrodes have been prelithiated between 2.5 and $0.01 \mathrm{~V}$ for three cycles with a three-electrode setup and ended at $0.1 \mathrm{~V}$ to store sufficient lithium in the negative electrode. The lithium counter electrode is then removed, and the positive KPN900 electrode is placed on top of the negative electrode covered with the separator. After a few cycles of charge and discharge, 
the impedance of the 4:1 cell is measured with a frequency analyzer. The impedance results of the full cell with the LiTFSI electrolyte are less than those of the $\mathrm{LiPF}_{6}$ cell, Fig. S5b. The magnitude difference between LiTFSI and $\mathrm{LiPF}_{6}$ cells is less at high frequency, and increases with decreasing frequency. The two impedance results are fitted with an equivalent circuit, which includes an electrolyte resistance $R_{S}$, in series with a pair of resistance and Warburg element $R_{1} / W_{1}$, a pair of resistance and constant phase element, $R_{2} / C P E_{2}$, and a constant phase element $C P E_{1}$. The total resistance, $R_{S}+R_{1}+R_{2}$, is $19.3 \Omega$ for the LiTFSI cell, and $35.0 \Omega$ for the $\mathrm{LiPF}_{6}$ cell.
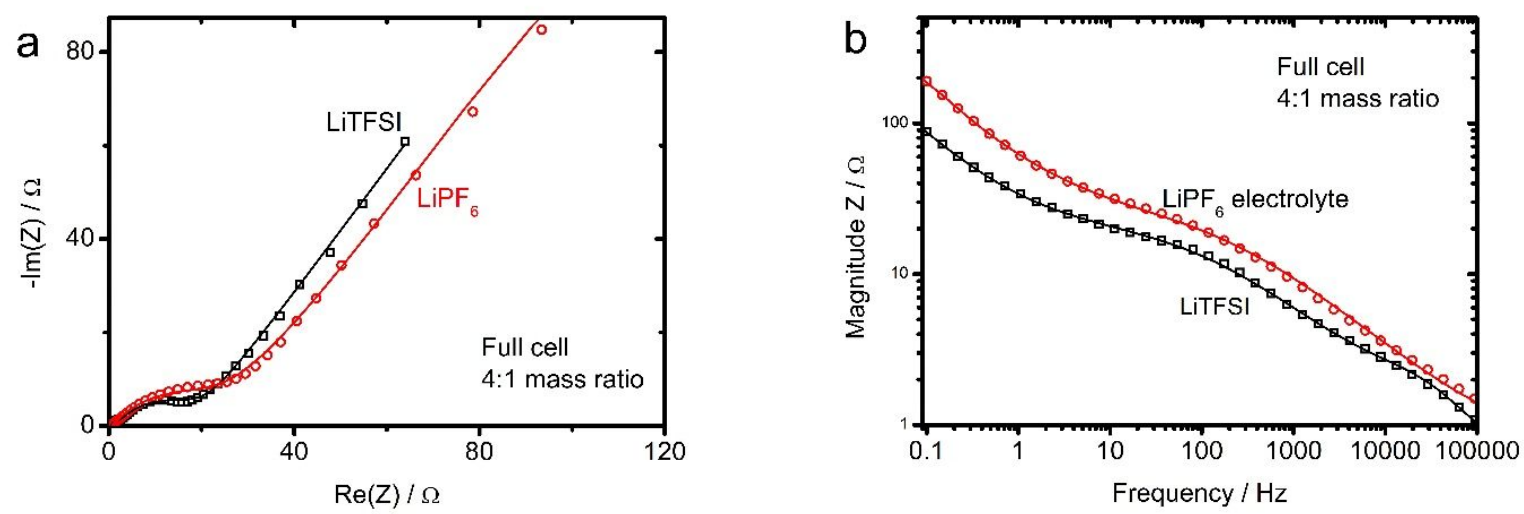

Fig. S5 Impedance comparison between the full cells of LiTFSI and $\mathrm{LiPF}_{6}$. The two cells have similar loadings of active materials, one is soaked in LiTFSI electrolyte, and the other is in $\mathrm{LiPF}_{6}$ electrolyte. The two Nyquist plots are shown in Fig. S5(a); while the two Bode plots are illustrated in Fig. S5(b). 
Voltage partition is influenced by multiple factors, such as electrode capacities, prelithiation, mass ratio, and charging current. For the 4:1 full cell of KPN900//SnS-Sn/CNT in LiTFSI, $\Delta U_{+}$and $\Delta U_{-}$values vary with charging current systematically, as shown in Fig. S6.
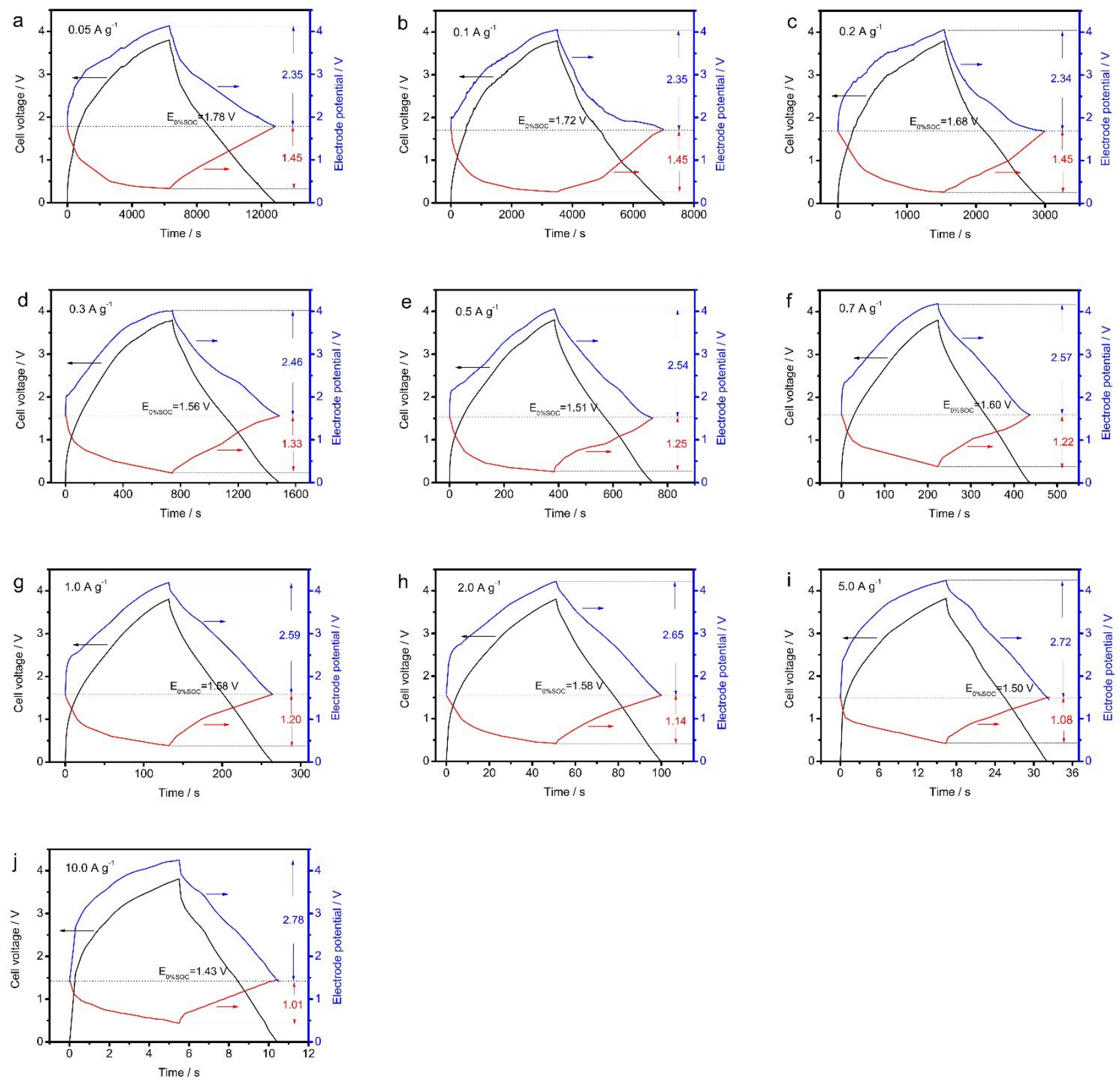

Fig. S6 Voltage profiles and electrode potential profiles of the 4:1 full cell of KPN900//SnS-Sn/CNT with a negative $5 \mathrm{SnS}-5 \mathrm{Sn} / \mathrm{CNT}$. The electrolyte is $1.0 \mathrm{M} \mathrm{LiTFSI}$ and $0.2 \mathrm{M} \mathrm{LiNO}_{3}$ in an ether-based solution. The cell voltage profiles, positive and negative potentials, during charge discharge in $3.8 \mathrm{~V}$ voltage window, are plotted for (a) 0.05, (b) 0.1 (c) 0.2, (d) 0.3, (e) 0.5, (f) 0.7, (g) 1.0, (h) 2.0, (i) 5.0, (j) $10.0 \mathrm{~A} \mathrm{~g}^{-1}$. 